\title{
New better design for water-water heat pumps
}

\author{
C. J. Renedo, A. Ortiz, M. Mañana, S. Pérez, F. Delgado, D. Silió, F. Ortiz \\ Department of Electrical and Energy Engineering, University of Cantabria \\ Av Los Castros s/n, 39005 Santander, Cantabria \\ Tlfn $0034942201382 \quad$ Fax 0034942201385 \\ renedoc@unican.es
}

\begin{abstract}
.
In air conditioning facilities most of the energy consumption corresponds to the thermal production, this being heat and cold. It depends on many factors, one of the most important in the use of more efficient devices (boilers, chillers and heat pumps)for supply thermal energy. In this work the efficiency of the reversible waterwater heat pumps is analyzed, proposing a new better design that optimizes the nergy consumptiom. This improvement hardly requires modifications at manufacturing, therefore, it could be easily developed by manufacturers.
\end{abstract}

\section{Key words}

water-water heat pump, counterflow, parallel flow, efficiency

\section{Introduction}

Nowadays, the quality of life has caused people to request thermal comfort and indoor air quality in buildings. This requires heating, venting and air conditioning systems (HVAC), whose market in Spain and Europe is growing $[1,2]$.

This thermal supply can be accomplished with chillers, heat pumps, boilers, etc., it being in these elements of the HVAC system where the energy consumption is higher. In this way, any improvement in energy efficiency in the thermal generation results in better global efficiency.

The heat pumps transfer heat from an area at low temperature to another at high temperature. This is usually carried out through the refrigeration cycle by vapour compression, taking advantage of the heat given off by the condenser.

A heat pump is reversible when advantage can be taken of the heat given off by the condenser, or the heat absorbed by the evaporator, depending on the thermal demand.

In this way, the thermal capacity definition of a reversible heat pump $\left(\mathrm{HP}_{\mathrm{TH}}\right)$, as well as the coefficient of performance (COP), are variable from winter to summer. In winter the $\mathrm{HP}_{\mathrm{TH}}$ is the heat given off by the condenser, while in summer it is the heat absorbed in the evaporator (Eq. 1).

$$
\left.\mathrm{HP}_{\mathrm{Th}}\right|_{\mathrm{W}}=\left.\dot{\mathrm{Q}}_{\mathrm{con}}\right|_{\mathrm{W}} ;\left.\mathrm{HP}_{\mathrm{Th}}\right|_{\mathrm{S}}=\left.\dot{\mathrm{Q}}_{\mathrm{eva}}\right|_{\mathrm{S}}
$$

The COP in winter is the quotient between the heat given off by the condenser and the work supplied to the compressor. In summer it is defined as the quotient between the heat absorbed by the evaporator and the work supplied to the compressor (Eq. 2).

$$
\begin{gathered}
\left.\mathrm{COP}\right|_{\mathrm{W}}=\left.\frac{\dot{\mathrm{Q}}_{\text {con }}}{\mathrm{W}_{\text {comp }}}\right|_{\mathrm{W}}=\left.\frac{\dot{\mathrm{Q}}_{\text {con }}}{\dot{\mathrm{Q}}_{\text {con }}-\dot{\mathrm{Q}}_{\mathrm{eva}}}\right|_{\mathrm{W}} ; \\
\left.\mathrm{COP}\right|_{\mathrm{S}}=\left.\frac{\dot{\mathrm{Q}}_{\mathrm{eva}}}{\mathrm{W}_{\text {comp }}}\right|_{\mathrm{S}}=\left.\frac{\dot{\mathrm{Q}}_{\mathrm{eva}}}{\dot{\mathrm{Q}}_{\text {con }}-\dot{\mathrm{Q}}_{\mathrm{eva}}}\right|_{\mathrm{S}} \text { Eq. }
\end{gathered}
$$

The COP of a heat pump increases when the difference between condensation and evaporation temperatures decreases [3].

Currently, reversible heat pumps have a great potential, especially in climates where the winter is not actually very cold, as is the case of areas with a Mediterranean climate [4].

Reversible water-water heat pumps are very similar to chillers, only requiring the addition of a reversing valve to invert the cycle, and a few auxiliary elements, as are check valves, or refrigerant receivers [5]. By means of the reversing valve, refrigerant flow direction is inverted, causing the condenser to become the evaporator, and the evaporator the condenser, Fig 1.

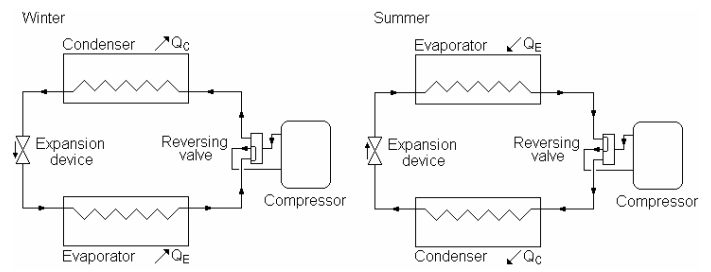

Fig 1. Reversible heat pump

Thus, with practically the same initial investment that a chiller requires, it is possible to purchase a machine that 
is able to accomplish the thermal demand throughout the year. So, heat pumps can be an economical solution for HVAC systems.

In this work the influence of the constructive form of a reversible water-water heat pump on its energy efficiency has been studied, proposing a system that reduces the annual energy consumption.

\section{Water-water heat pump}

In the water-water heat pumps heat is transferred from cool water to warm water, and if it is reversible, heat or cool water could be used depending on HVAC system thermal demand. Currently, this kind of machine is very common on the market, there being a great variety of manufacturers and models $[1,6]$.

If the heat pump is to have high efficiency throughout the year, the following conditions need to be met simultaneously:

- The indoor heating system should be supplied at low temperature [7].

- The cooling should be done at high temperature [8].

- The outside area should not have extreme temperatures, neither too low in winter, nor too high in summer.

The reversible water-water heat pumps make it possible to obtain better performances than those for the reversible air-air heat pumps. This is because, when the climate is rigorous, the outside air temperature is more unfavourable than that of the water from a well, river, lake, or the one of the ground, as much in summer as in winter. Ground water-water heat pumps take advantage of the energy stored in the ground, making the outside water flow through a buried coil. It is possible to implement this system with multiple possibilities, [9].

In this way, the operation of a reversible water-water heat pump, when the indoor HVAC systems is based on radiant surfaces and the outside system takes advantage of the water or ground energy, is characterized by [10]:

- Constant operation parameters, since the outside ground or water temperatures as well as the indoor ones are relatively constant.

- Good performance, since the temperature difference between the condensation and the evaporation is relatively small.

Regarding the possible disadvantages that the use of reversible water-water heat pumps can provoke, three of them are considered below:

- Different annual efficiency of the two heat exchangers (condenser and evaporator). The way in which these operate could be in parallel flow or in counterflow. From summer to winter operation the refrigerant direction changes while the water direction remains constant. So, it is not possible for the two heat exchangers to operate in counterflow all year long.

- The expansion device presents a preferential direction, and by inverting the refrigerant flow direction, the efficiency decreases with respect to the maximum possible.

- In addition, any freezing risk in the evaporator should be avoided.

\subsection{The heat exchangers operation}

The heat pumps have two heat exchangers: one works as an evaporator in the summer cycle and as a condenser in the winter cycle, while the other has the opposite effect, in summer it is a condenser, and in winter an evaporator. It is known that the operation of a heat exchanger is better in counterflow than in parallel flow [11].

On inverting the operation cycle of a water-water heat pump, the operation of the heat exchangers are also inverted since the refrigerant flow direction is changed, maintaining the water flow direction. Therefore, there is an operation period in which they operate in parallel flow with less efficiency.

In Fig 2 the scheme of the heat pump connection in winter, with the condenser and the evaporator in counterflow, and in summer, with the condenser and the evaporator in parallel flow, are shown.
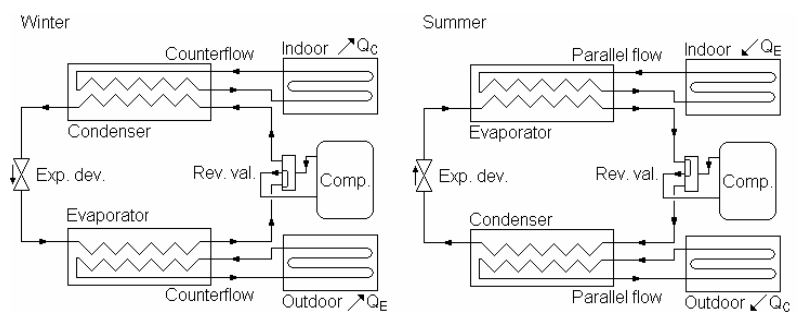

Fig 2. Change on the operation cycle in a Reversible water-water heat pump

The effects of changing refrigerant flow direction, in the condenser and in the evaporator, on the refrigeration cycle are shown in Fig. 3:

- It increases the high pressure,

- It increases the work required in compressor,

- It reduces the heat absorbed in the evaporator;

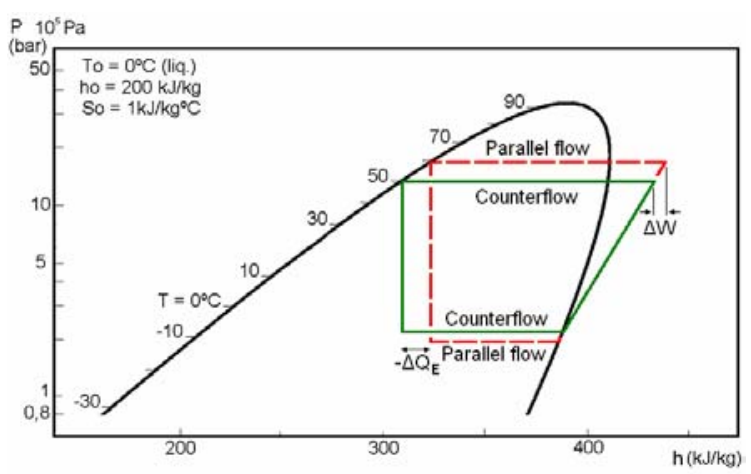

Fig 3. Effects of changing the refrigerant flow direction 
It is possible to connect the two heat exchangers in counterflow, but an external operation is needed. The water directions in the heat exchangers must be changed when the heat pump cycle changes from winter to summer, Fig 4.
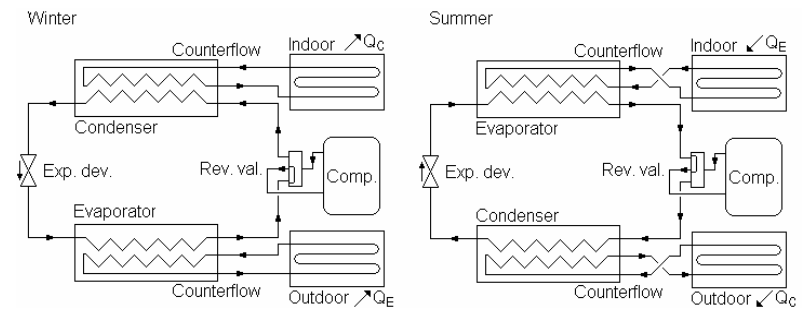

Fig 4. Change heat exchangers connections for keeping heat exchangers on counterflow

This solution does not avoid the problem created with the refrigerant flow direction in the expansion device.

\subsection{The expansion device}

The expansion device of the heat pump can operate in the two directions, but one of them offers better efficiency than the other.

By inverting the heat pump operation, the refrigerant flow direction is changed in the expansor, Figs 2 and 4. Therefore, the efficiency of the heat pump, in one of the two operation ways has been reduced from the maximum.

\section{Study of possibilities}

\subsection{System with cycle inversion}

The current system to optimize the efficiency of the heat pump is based on the knowledge of the operation time of the heat pump during both the summer cycle and the winter cycle.

In [12], the results of configuration trials for the heating and cooling period for a $15 \mathrm{~kW}$ water-water heat pump are presented. It is observed that, depending on the configuration, the COP can be reduced, with respect to the maximum obtainable, down to values around $86 \%$ in winter and $82 \%$ in summer. Obviously, the better configuration for summer is the worse in winter and conversely.

Currently, to optimize the energy consumption of the heat pump thermal demand should be considered. If it is greater in summer, the most favourable configuration for the summer is adopted; and if it is greater in winter, the most favourable configuration for winter is used. For the case of homogeneous consumption throughout the year, an intermediate configuration is implemented.

Supposing that the preferential flow direction in the expansor, according the figures, is downward, then the optimum configuration, when the greater consumption corresponds to the winter, is represented in Fig 2. The other 4 possible connection configurations are represented in Fig 5.
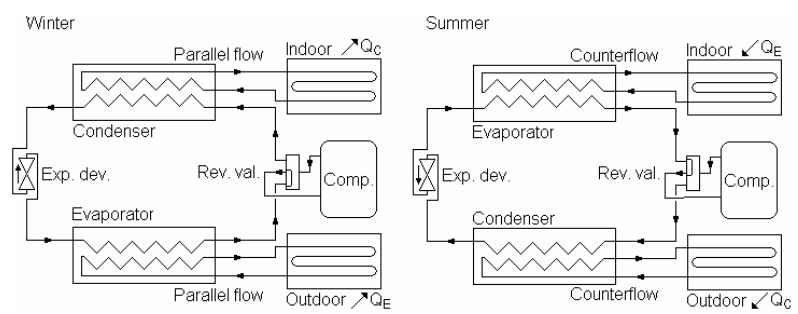

a) Connection with preference for summer consumption
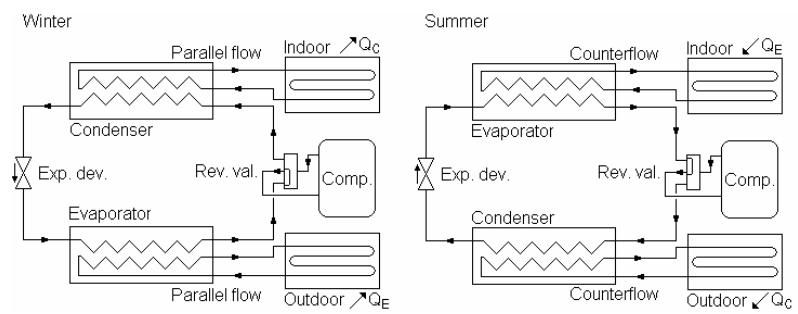

b) Connection 1 for balanced consumption
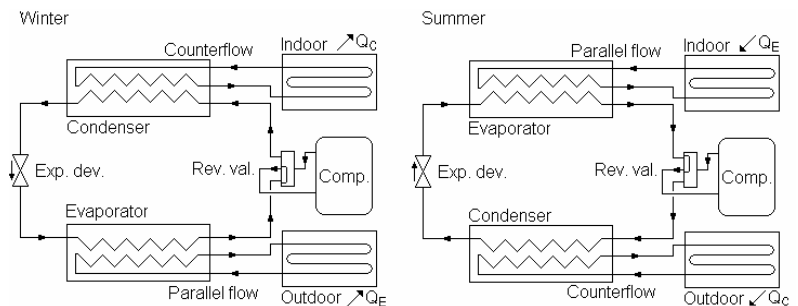

c) Connection 2 for balanced consumption
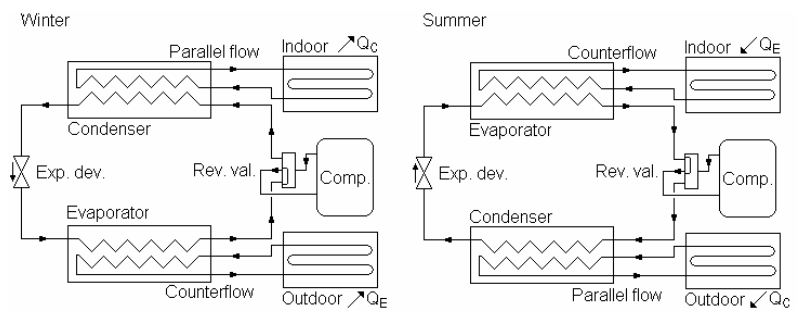

d) Connection 3 for balanced consumption

Fig 5. Possible connections for a reversible water-water heat pump

\subsection{ASHRAE}

ASHRAE in [8], proposes a design in which the reversible water-water heat pump is not achieved by inverting the refrigerating cycle, but changing the water connections by means of four 3 -way valves. In this way, the heat exchangers of the heat pump are always connected on counterflow, and the direction of the refrigerant in the expansion device is always in the preferential direction.

In the ASHRAE design, the condenser is installed in parallel flow. We propose a more favourable design based on the same type of solution, Fig 6, connecting the two heat exchangers in counterflow.

The system of cycle inversion improves the ASHRAE design since, though the heat exchangers always circulate the same, indoor or outdoor, water. It represents a great practical advantage when the outside water is an open circuit (well or river waste water, ...), because, in this way, it is possible to use secondary coolants like propylene glycol or ethylene glycol in the indoor circuit and to avoid the fouling in the heat exchanger. 

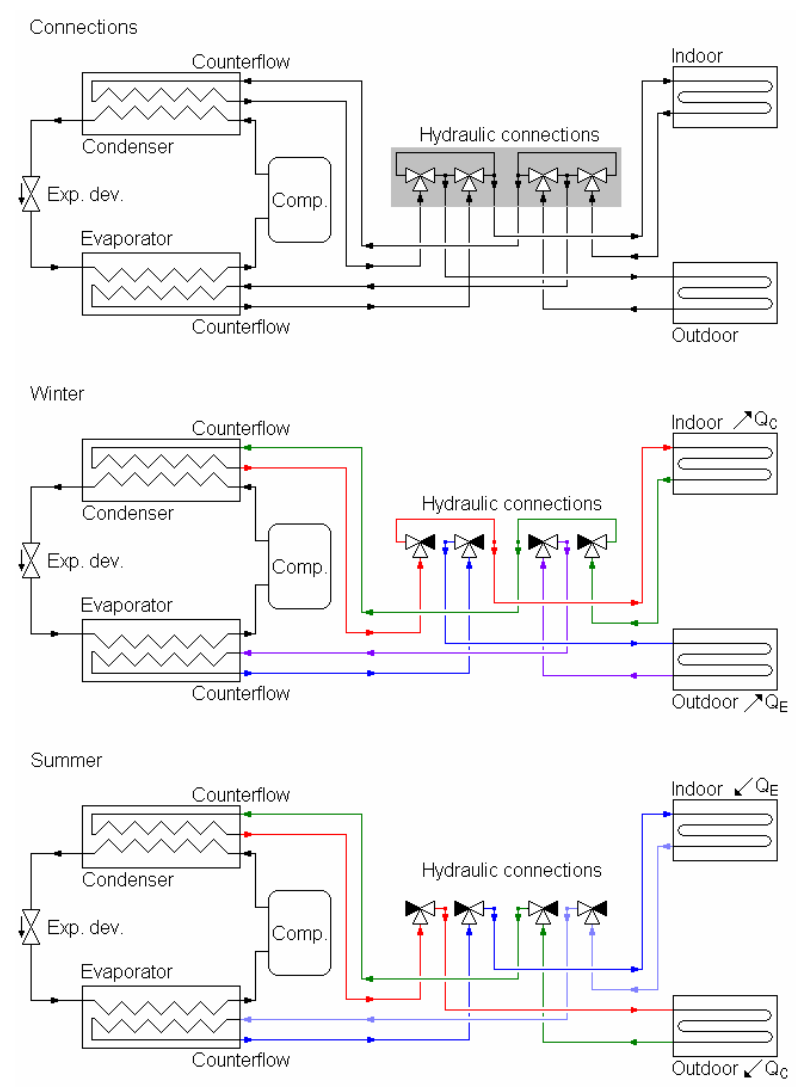

Fig 6. ASHRAE design improved

\subsection{New system design}

The new proposed solution does not invert the cycle of the heat pump, but inverts the direction of the water flows, as in the ASHRAE design.

The heat pump is a common chiller with water condensation and without cycle inversion. The reversible mode is based on a hydraulic system located outside the chiller. It can be performed manually, changing the water connections, Fig 7, or by a hydraulic module. At this point we propose two reversing valves, Fig 8, instead of the four 3-way valves proposed by ASHRAE. This design reduces the number of elements, thereby reducing material cost and installation time.
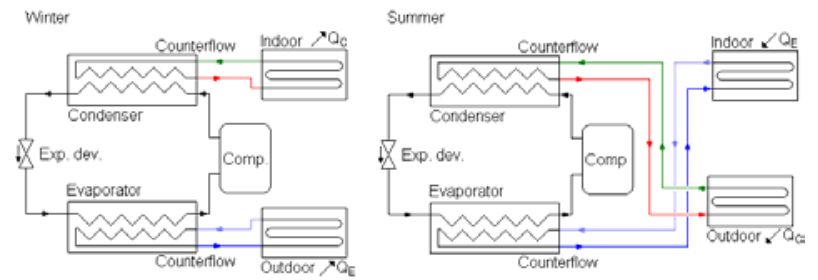

Fig 7. Optimum design changing water connections

A reversible water-water heat pump working at optimum efficiency throughout the year is obtained with the configuration proposed. Thus, the expansor always works with the refrigerant flow in the preferential direction, while both the evaporator and condenser are in counterflow all year long.

As in the ASHRAE design, this new concept is able to use a conventional chiller as a reversible water-water heat pump, since the hydraulic module can be incorporated at any time outside the machine.
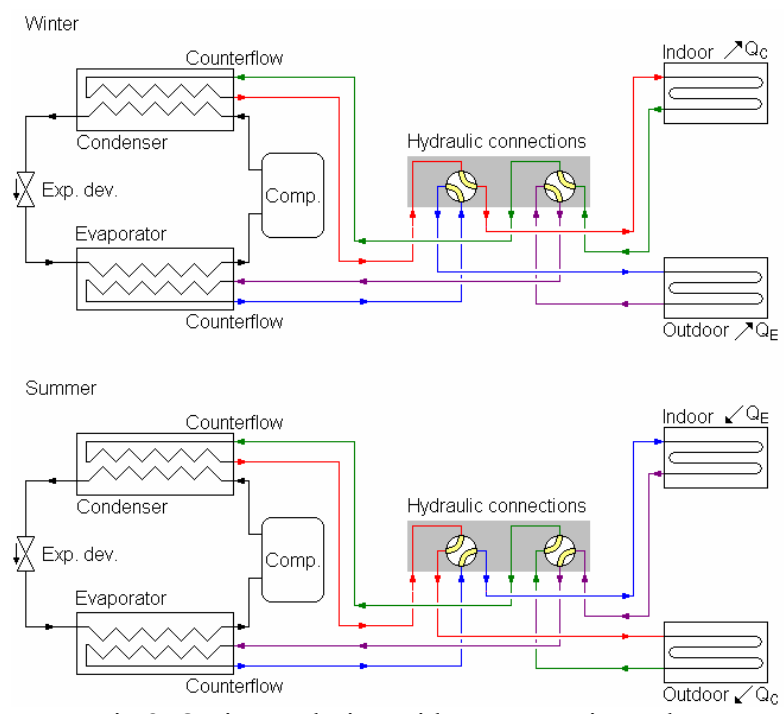

Fig 8. Optimum design with two reversing valves

\section{Efficiency analysis}

Several tests were performed to establish the COP and the capacity of a $20 \mathrm{~kW}_{\text {th }}$ reversible water-water heat pump. The trials took into account the configurations previously undertaken, (Fig 2, 5a, 5b, 5c and 5d) [13]. The results are shown in Table 1.

Table 1. Experimental data

\begin{tabular}{|c|c|c|c|c|}
\cline { 2 - 5 } \multicolumn{1}{c|}{} & \multicolumn{2}{c|}{ Capacity $\left(\mathrm{kW}_{\text {th }}\right)$} & \multicolumn{2}{c|}{ COP } \\
\hline Fig & Winter & Summer & Winter & Summer \\
\hline 2 & 20,62 & 16,73 & 3,58 & 3,29 \\
\hline 5a & 19,39 & 23,42 & 3,06 & 3,99 \\
\hline $5 \mathrm{~b}$ & 18,97 & 17,99 & 3,22 & 3,75 \\
\hline 5c & 20,07 & 17,38 & 3,47 & 3,55 \\
\hline $5 \mathrm{~d}$ & 19,40 & 17,34 & 3,29 & 3,5 \\
\hline
\end{tabular}

In order to determine the heat pump energy consumption six different types of thermal demands have been taken into account, going from solely demand in winter up to having solely demand in summer, with intermediate situations like the same demand in winter as in summer. Table 2. To study the influence of this parameter the annual demand considered was $30,000 \mathrm{kWh}_{\mathrm{th}}$.

Table 2. Six different scenarios for annual thermal demand $\left(\mathrm{kWh}_{\mathrm{th}}\right)$

\begin{tabular}{|c|c|c|c|}
\cline { 2 - 4 } \multicolumn{1}{c|}{} & $\mathrm{hW}$ & $\mathrm{hW}=2 \mathrm{hS}$ & $\mathrm{hW}=3 / 2 \mathrm{hS}$ \\
\hline Winter & 30,000 & 20,000 & 18,000 \\
\hline Summer & 0 & 10,000 & 12,000 \\
\hline \multicolumn{3}{c}{} \\
\cline { 2 - 4 } \multicolumn{1}{c|}{} & $\mathrm{hW}=\mathrm{hS}$ & $\mathrm{hW}=2 / 3 \mathrm{hS}$ & $\mathrm{hS}$ \\
\hline Winter & 15,000 & 12,000 & 0 \\
\hline Summer & 15,000 & 18,000 & 30,000 \\
\hline
\end{tabular}

Considering the design outlined in Fig 8, the maximum efficiency and the maximum capacity from the heat pump would be obtained for each situation, since the two heat 
exchanges operate in counterflow, and the expansion device in the preferential direction.

The results of the annual electrical consumption for supplying the thermal demand, depending on the heat pump configuration, are shown in Fig 9. The four scenarios with winter and summer demand have been considered, and the consumption has been divided between summer and winter.

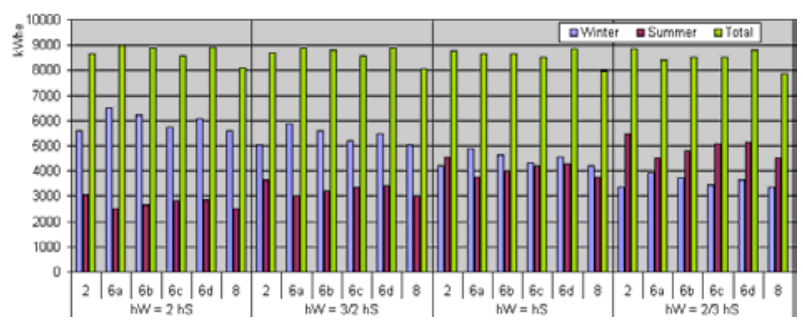

Fig 9. Electric energy consumption with 4 demand scenarios

In Fig 9, it can be observed how the proposed design improves the energy consumption, for any scenario considered.

The total electric consumption for the six considered thermal demand scenarios are represented in Fig 10.

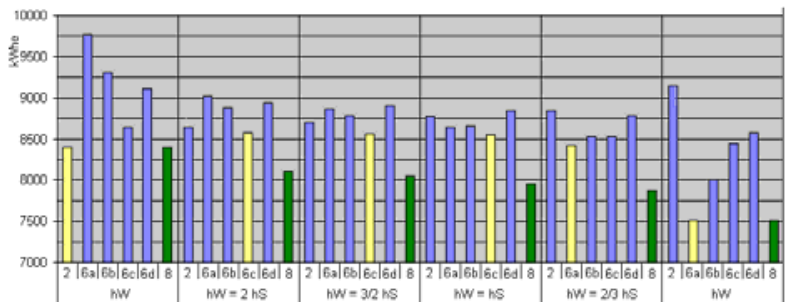

Fig 10. Detail of electric energy consumption for the six scenarios of thermal demand

In Fig 10, it can be observed how the proposed design minimizes the electric consumption for any scenario with thermal demand all year long.

The configuration proposed produces improvements higher than $5 \%$, except when the thermal demand is only required in winter or in summer, since in these situations the operation proposed works as configurations 2 and $6 \mathrm{a}$, respectively.

\section{Conclusions}

The air conditioning is in increasing demand in commercial and office buildings. In warm climates winter does not have extreme temperatures and therefore the heat pump is able to supply, with a very acceptable performance, the space heating.

Due to the air conditioning systems requires a chiller and a heater, a heat pump is very competitive, since the initial heating cost is negligible compared with a boiler system.

In this work, the design of exisitng reversible water-water heat pumps has been analysed from an energy point of view.
A new design with better efficiency has been presented. The reduction in the annual electrical demand depends on the profile of the thermal consumption, but in general it could be cut down by more than $5 \%$. The design does not means a significant increment of the heat pump cost, because it only needs an additional reversing valve (refrigerant changeover design), or the substitution of the four three ways valves for two reversing valves (ASHRAE design).

According to references $[5,6]$, an electrical heat pump reduces approximately $50 \%$ of $\mathrm{CO}_{2}$ emissions of a gas oil boiler and $70 \%$ of a natural gas boiler. Thus, the use of heat pumps in heating systems will contribute towards reducing the greenhouse effect.

\section{References}

[1] AFEC, http://www.afec.es/

[2] EUROVENT-CECOMAF, http://www.euroventcecomaf.org/web/eurovent/web/

[3] M. J. Moran, H. N. Shapiro, Fundamentals of Engineering Thermodynamics, Ed John Wiley \& Sons, Inc.

[4] IDAE, http://www.idae.es/

[5] HVAC Systems and Equipment, ASHRAE, 2000

[6] ENEBEC, http://www.enebc.org/

[7] M. Ortega, A. Ortega, Calefacción y refrescamiento por superficies radiantes, Ed Thomson Learning ,2000.

[8] Fundamentals, ASHRAE, 2001

[9] http://geoheat.oit.edu

[10] IDAE, Documento Técnico de la Bomba de Calor, 1998

[11] F.P. Incropera, D.P. DeWitt "Fundamentals of Heat and Mass transfer" John Wiley and Sons, Inc. 1996.

[12] I. Martínez et al. Estudio de Caracterización de una Bomba de Calor Agua-Agua usando R407 como Refrigerante, XVI Congreso Español de Ingeniería Mecánica, Vol 1, pg 503-512

[13] C. J. Renedo et al., Energy and Buildings, (38) 2006 $1240-1247$ 